Gulde, R., Helbling, D. E., Scheidegger, A., \& Fenner, K. (2014). pH-dependent biotransformation of ionizable organic micropollutants in activated sludge. Environmental Science and Technology, 48(23), 13760-13768. https:// doi.org/10.1021/es5037139

\title{
pH-dependent Biotransformation of Ionizable Organic Micropollutants in Activated Sludge
}

Rebekka Gulde, ${ }^{\dagger} \ddagger$ Damian E. Helbling, ${ }^{\top}$ Andreas Scheidegger, ${ }^{\dagger}$ and Kathrin Fenner*,,+

Eawag, Swiss Federal Institute of Aquatic Science and Technology, 8600 Dübendorf,

Switzerland, Department of Environmental Systems Science (D-USYS), ETH Zürich, 8092

Zürich, Switzerland, and School of Civil and Environmental Engineering, Cornell University,

Ithaca, NY, USA

E-mail: kathrin.fenner@eawag.ch

Phone: +4158765 5085. Fax: +4158765 5802

Abstract
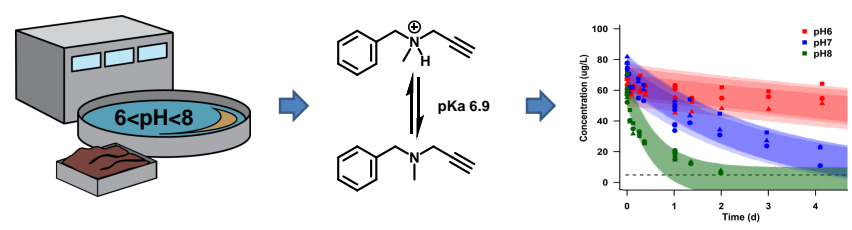

* To whom correspondence should be addressed

${ }^{\dagger}$ Eawag, Swiss Federal Institute of Aquatic Science and Technology, 8600 Dübendorf, Switzerland

${ }^{\ddagger}$ Department of Environmental Systems Science (D-USYS), ETH Zürich, 8092 Zürich, Switzerland

ISchool of Civil and Environmental Engineering, Cornell University, Ithaca, NY, USA 
Removal of micropollutants (MPs) during activated sludge treatment can mainly be attributed to biotransformation and sorption to sludge flocs, whereby the latter process is known to be minor for polar organic micropollutants. In this work, we investigated the influence of $\mathrm{pH}$ on the biotransformation of MPs with cationic-neutral speciation in an activated sludge microbial community. We performed batch biotransformation, sorption control, and abiotic control experiments for $15 \mathrm{MPs}$ with cationic-neutral speciation, one control MP with neutral-anionic speciation, and two neutral MPs at $\mathrm{pHs} 6,7$, and 8. Biotransformation rate constants corrected for sorption and abiotic processes were estimated from measured concentration time series with Bayesian inference. We found that biotransformation is $\mathrm{pH}$-dependent and correlates qualitatively with the neutral fraction of the ionizable MPs. However, a simple speciation model based on the assumption that only the neutral species is efficiently taken up and biotransformed by the cells tends to overpredict the effect of speciation. Therefore, additional mechanisms such as uptake of the ionic species and other more complex attenutation mechanism are discussed.Finally, we observed that the sorption coefficients derived from our control experiments were small and showed no notable $\mathrm{pH}$-dependence. From this we conclude that $\mathrm{pH}$-dependent removal of polar, ionizable organic MPs in activated sludge systems is less likely an effect of $\mathrm{pH}$-dependent sorption but rather of $\mathrm{pH}$-dependent biotransformation. The latter has the potential to cause marked differences in the removal of polar, ionizable MPs at different operational pHs during activated sludge treatment.

\section{Introduction}

A variety of organic micropollutants (MPs) are conveyed by sanitary sewers or by surface runoff and storm water sewers to wastewater treatment plants (WWTPs) where they are partially removed during activated sludge treatment. ${ }^{1,2}$ The extent of removal within a WWTP is known to vary among different MPs due to different chemical properties, as well as for single MPs between different WWTPs. ${ }^{1,3}$ The latter case is attributed to differences in operational parameters of the WWTPs such as total suspended solids concentration (TSS), solids and hydraulic retention times, 
dissolved oxygen, temperature, and $\mathrm{pH} .{ }^{4}$ However, so far no single operational parameter has been identified that can explain differences in removal efficiency for a range of MPs between different WWTPs. ${ }^{5}$ Rather, there might be varying degrees of influence of the operational parameters on the removal efficiency of different MPs. Because a complex mixture of only partially removed MPs in WWTP effluents can negatively affect water quality, ${ }^{6}$ it is of interest to understand how operational parameters influence MP removal.

The $\mathrm{pH}$ of activated sludge systems in WWTPs is one such operational parameter and can vary by nearly two $\mathrm{pH}$ units; across 10 Swiss WWTPs, the $\mathrm{pH}$ of activated sludge samples ranged from 6.2 to $8.1 .{ }^{5}$ At the same time, many MPs entering the WWTPs contain ionizable functional groups with $\mathrm{p} K_{\mathrm{a}}$ values within that $\mathrm{pH}$ range. For instance, around $40 \%$ of pharmaceuticals, which are a dominant substance class in wastewater influents, ${ }^{7}$ contain at least one functional group with $\mathrm{p} K_{\mathrm{a}}$ values in the range of $5-10$ and cationic-neutral speciation, ${ }^{8}$ and about $10 \%$ contain at least one functional group with neutral-anionic speciation in the same $\mathrm{p} K_{\mathrm{a}}$ range. Thus, the degree of speciation of such ionizable MPs will vary across activated sludge systems with different operational $\mathrm{pHs}$.

Previous studies have shown that the removal efficiency for MPs with ionizable functional groups is $\mathrm{pH}$-dependent. ${ }^{9-11}$ Removal during activated sludge treatment can mainly be attributed to biotransformation and sorption to activated sludge. Because chemical speciation can influence sorption as well as biotransformation, both processes could potentially lead to $\mathrm{pH}$-dependent removal.

$\mathrm{pH}$-dependent sorption of organic MPs to activated sludge was studied previously for MPs with neutral-anionic speciation. ${ }^{9,10}$ For these MPs, a decrease in sorption affinity was observed at higher $\mathrm{pH}$ levels where the fraction of anionic species is increased. The surface of activated sludge flocs is predominantly negatively charged. ${ }^{12}$ As a result, it is assumed that the sorption affinity is weakened at higher $\mathrm{pH}$ levels by the increased solubility of the charged species in water and the increased electrostatic repulsion between the negatively charged MPs and the activated sludge flocs. pH-dependent sorption of MPs with cationic-neutral speciation is considerably less 
well understood. In this case, it is more difficult to formulate expectations on how sorption affinities change with $\mathrm{pH}$, due to several contributing factors. First, the negative charge of the sludge flocs is expected to decrease with decreasing $\mathrm{pH},{ }^{12}$ while the fraction of positively charged compounds increases with decreasing $\mathrm{pH}$ for MPs with cationic-neutral speciation. Hence, the extent of electrostatic interaction of the cations with the negatively charged flocs could already result in different $\mathrm{pH}$-trends depending on the particular speciation behavior of the sludge and the MP in question. Second, positively charged compounds exhibit not only an increased electrostatic interaction with the predominantly negatively charged flocs, but are also more water-soluble than the corresponding neutral species, which are opposing trends. Third, other factors like the ionic strength and the ionic composition of the bulk medium are known to affect the sorption affinity of the cationic species as well. ${ }^{13,14}$ Therefore, it is not surprising that some studies observed no systematic trend of the sorption behavior of MPs with cationic-neutral speciation with $\mathrm{pH},{ }^{15,16}$ whereas other studies did. ${ }^{17}$ Finally, although the sorption affinity of ionizable MPs may vary in the $\mathrm{pH}$ range of $6-8$, the majority of MPs entering the WWTPs are rather polar ${ }^{18}$ with sorption coefficients $\left(K_{\mathrm{d}}\right)$ typically $<300 \mathrm{~L} / \mathrm{kg} .{ }^{19}$ It has therefore been suggested that sorption is not a significant process for the removal of polar organic MPs in WWTPs. ${ }^{20}$ Consequently, we do not expect sorption to cause a significant $\mathrm{pH}$-dependence in overall removal.

Rather, several possible effects of $\mathrm{pH}$-induced chemical speciation on MP biotransformation seem plausible. If the enzymes responsible for biotransformation are extracellular, chemical speciation could influence the interaction affinity between MPs and enzymes because enzymes often have high affinities for only one species of a given substrate. For example, ammonia monooxygenase can utilize $\mathrm{NH}_{3}$ as a substrate but not $\mathrm{NH}_{4}^{+}$, which is thought to explain the known $\mathrm{pH}$-dependence of nitrification. ${ }^{21,22}$ In the case of MP removal through oxidative transformation, the majority of enzymes are expected to be intracellular because of their dependence on enzymatic co-factors and their coupling to the electron transfer chain. Thus, in the more likely case of intracellular biotransformation, chemical speciation might directly affect uptake efficiency since charged species are less likely to permeate cell membranes. ${ }^{23}$ This mechanism is also commonly 
used to explain observations of $\mathrm{pH}$-dependent toxicity of ionizable compounds, for which it was shown that toxicity typically increases under $\mathrm{pH}$ conditions where the majority of the compound is present as neutral species. ${ }^{24}$

All three studies ${ }^{9-11}$ that examine $\mathrm{pH}$-dependent removal of ionizable MPs in WWTPs so far investigated MPs with neutral-anionic speciation. In those studies, a clear $\mathrm{pH}$-dependence was observed, with increasing removal efficiencies at lower $\mathrm{pHs}$ where the neutral fraction of the MPs is higher. Although in the three studies additional experiments were conducted to account for sorption, it remained difficult to clearly disentangle the effects of $\mathrm{pH}$-dependent biotransformation and sorption. All three studies concluded that the observed higher sorption affinities of the neutral species led to increased removal efficiencies. But only Tadkaew et al. (2010) explicitly considered sorption to sludge and subsequent withdrawal of excess sludge as the mechanism behind the observed pH-dependent removal. In contrast, Urase and Kikuta (2005) as well as Kimura et al. (2010) interpreted sorption as a necessary first step in the biotransformation process. Thus, they seemed to suggest that close proximity to the cells and subsequently, enhanced uptake into the cells explains the observed $\mathrm{pH}$-dependence.

The difficulty in investigating the underlying mechanism of $\mathrm{pH}$-dependent removal of MPs with neutral-anionic speciation is that the $\mathrm{pH}$-dependence of sorption and the $\mathrm{pH}$-dependence of permeation through the cell membrane are aligned; namely, both processes show increasing efficiencies at lower $\mathrm{pH}$ levels. In this study, we focused on MPs with cationic-neutral speciation instead for two reasons. First, to our knowledge, the effect of varying $\mathrm{pH}$ on the removal of these MPs has not been explored so far. Second, the expected different effects of $\mathrm{pH}$ on sorption and biotransformation of compounds with cationic-neutral speciation might help to distinguish the contribution of these two processes on $\mathrm{pH}$-dependent removal of ionizable MPs in general. The goal of our research was to gain a more mechanistic understanding of the effect of varying $\mathrm{pH}$ on the biotransformation of ionizable, polar MPs. Specifically, we hypothesize that the biotransformation of MPs with cationic-neutral speciation correlates with their degree of speciation due to increased uptake efficiency of the neutral species, resulting in an increased 
biotransformation efficiency at higher $\mathrm{pH}$ levels. To test this hypothesis, we first performed biotransformation experiments, as well as sorption and abiotic control experiments, for 15 MPs with cationic-neutral speciation, two neutral MPs, and one MP with neutral-anionic speciation in a single activated sludge microbial community adjusted to three different $\mathrm{pH}$ levels. The latter three compounds were included to confirm that chemical speciation rather than a direct effect of $\mathrm{pH}$ on sludge viability and structure was the major reason for any observed $\mathrm{pH}$-dependence. We then quantified the $\mathrm{pH}$-dependence of the biotransformation rate constants corrected for abiotic and sorption processes for all $18 \mathrm{MPs}$, and finally discuss the results in light of the potential underlying mechanisms.

\section{Materials and Methods}

\section{Micropollutant Selection}

We selected 18 environmentally relevant MPs including 15 that undergo cationic-neutral speciation, one that undergoes neutral-anionic speciation, and two MPs that remain predominately neutral in the $\mathrm{pH}$ range investigated. Chemical structures as well as $\mathrm{p} K_{\mathrm{a}}$ values are presented in Table 1. All MPs with cationic-neutral speciation contain an amine functional group. The $\mathrm{p} K_{\mathrm{a}}$ of seven of these MPs was in the usual range for aliphatic amines between 9.1 and 10.0 (atenolol, mexiletine, pheniramine, primaquine, pyrilamine, propranolol, and venlafaxine). The other eight amines were selected to exhibit a lower $\mathrm{p} K_{\mathrm{a}}$ in the range between 6.9 and 8.4 (1(3-chlorophenyl)piperazine, deprenyl, lidocaine, mianserin, nicotine, orphenadrine, pargyline, and pramoxine). The MP with neutral-anionic speciation is trinexapac-ethyl. The two neutral MPs, azoxystrobin and isoproturon, were selected to control for direct effects of $\mathrm{pH}$ changes on the viability, structure, and sorption capacity of the activated sludge. MPs were purchased from Dr. Ehrenstorfer GmbH (Augsburg, Germany), Sigma-Aldrich Chemie GmbH (Buchs, Switzerland), Lipomed AG (Arlesheim, Switzerland), and Toronto Research Chemicals (Toronto, Canada). 
Table 1: Compound ID, Compound Name, Structure, $\mathrm{p} K_{\mathrm{a}}$ Values with Reference

\begin{tabular}{|c|c|c|c|c|}
\hline & ID & Name & Structure & $\mathrm{p} K_{\mathrm{a}}$ \\
\hline \multirow{15}{*}{ 莫 } & PAR & Pargyline & & $6.9^{25}$ \\
\hline & MIA & Mianserin & & $6.9^{26}$ \\
\hline & PRA & Pramoxine & & $7.1^{26}$ \\
\hline & DEP & Deprenyl & & $7.5^{27}$ \\
\hline & LID & Lidocaine & & $8.0^{27}$ \\
\hline & NIC & Nicotine & & $8.2^{27}$ \\
\hline & CHLO & $\begin{array}{l}\text { 1-(3- } \\
\text { chlorophenyl) } \\
\text { piperazine }\end{array}$ & & $8.4^{28}$ \\
\hline & ORP & Orphenadrine & & $8.4^{29}$ \\
\hline & PYR & Pyrilamine & & $9.1^{27}$ \\
\hline & MEX & Mexiletine & & $9.1^{30}$ \\
\hline & PHE & Pheniramine & & $9.3^{25}$ \\
\hline & VEN & Venlafaxine & & $9.4^{29}$ \\
\hline & PRO & Propranolol & & $9.6^{27}$ \\
\hline & ATE & Atenolol & & $9.6^{27}$ \\
\hline & PRI & Primaquine & & $10.0^{30}$ \\
\hline . $\frac{*}{\tilde{U}}$ & TRI & $\begin{array}{l}\text { Trinexapac } \\
\text {-ethyl }\end{array}$ & & $4.8^{31}$ \\
\hline$\frac{\pi}{ \pm}$ & ISO & Isoproturon & & \\
\hline 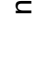 & $\mathrm{AZO}$ & Azoxystrobin & & \\
\hline
\end{tabular}

* Charge state of ionic species. 


\section{Biotransformation Test System}

The experimental set-up for the biotransformation batch experiments was adopted from Helbling et al. (2010a). ${ }^{32} \mathrm{pH}$ adjustment was done as described in Wick et al. (2009). ${ }^{33}$ The combined experimental set-up used in this study is given in the following. Activated sludge $(2.5 \mathrm{~L})$ was sampled from the nitrification basin of a half municipal and half industrial WWTP (ARA Neugut, Dübendorf, Switzerland) and was diluted with tap water $(1 \mathrm{~L})$, resulting in a TSS of approximately 2 gss $/ L$ (gss: gram suspended solids). This sludge was used for three different experiments, namely the biotransformation experiments (BEs), the sorption control experiments (SEs), and the abiotic control experiments (AEs). Each experiment was conducted at three $\mathrm{pH}$ levels in triplicate.

For the BEs, reactors (100 mL amber Schott bottles) were filled with $50 \mathrm{~mL}$ activated sludge and stirred at $130 \mathrm{rpm}$ on a multiple stir plate. Air or air $/ \mathrm{CO}_{2}$ (Carbagas, Gümligen, Switzerland) mixtures were distributed via lines that were connected with a Luerlock to a syringe tip (diameter: $0.6 \mathrm{~mm}$, length: $8 \mathrm{~mm}$, Carl Roth AG). The syringe tip was inserted into one of two holes in the cap of the batch reactors and adjusted to near the bottom of the reactors. Stirring and bubbling air through the medium ensured continuous mixing and aeration. $\mathrm{CO}_{2}(\mathrm{~g})$ was mixed at different ratios with pressurized air using rotameters (Aalborg, Orangeburg, USA). The mixing ratios were adjusted manually to establish approximate $\mathrm{pH}$ values of 6 and 7 in the respective reactors. Bubbling of air without additional $\mathrm{CO}_{2}$ was used in the remaining reactors to establish a $\mathrm{pH}$ value of approximately 8. BEs were started earliest one hour after $\mathrm{pH}$ adjustment and within six hours of activated sludge sampling. Then, $100 \mu \mathrm{L}$ of a MP mix solution (50 mg/L each in methanol:ethanol:DMSO 16:3:1) were spiked into each batch reactor, resulting in final concentrations of $100 \mu \mathrm{g} / \mathrm{L}$ for each MP. Kern et al. (2010) ${ }^{34}$ showed that biotransformation kinetics derived from similar batch experiments, in which the MP concentration was also roughly three orders of magnitude higher than in actual sewage, were appropriate to predict measured mass flows in actual WWTPs. Furthermore, we assume that by treating all reactors in the same way the comparison of kinetic parameters amongst $\mathrm{pH}$ values was still valid, even if the addition of 
the organic carbon of the solvent or other batch reactor adjustments might have caused a shift of the microbial community and/or the introduction of the MPs as a mixture instead of single MPs might have altered individual rate constants. Triplicate time zero samples were taken within five minutes after spiking. Subsequent samples were withdrawn at approximately $2 \mathrm{~h}, 4 \mathrm{~h}, 8 \mathrm{~h}, 1 \mathrm{~d}$ (in triplicate), $1.5 \mathrm{~d}, 2 \mathrm{~d}, 3 \mathrm{~d}$, and $4 \mathrm{~d}$ after the start of the experiment. At each time point, samples (approx. $1.5 \mathrm{~mL}$ ) were withdrawn from the reactor with a $10 \mathrm{~mL}$ glass syringe, transferred to a centrifuge tube $(1.7 \mathrm{~mL}$ Safeseal Microcentrifuge Tubes, Sorenson Bioscience, Inc.), and centrifuged for 10 minutes at approximately $13000 \mathrm{~g}$ (14000 rpm, ALC, micro centrifugette 4214). The supernatants $(0.5 \mathrm{~mL})$ were transferred into $2 \mathrm{~mL}$ amber vials and stored between 1 hour and 10 days at $4{ }^{\circ} \mathrm{C}$ in the dark until analysis. One unspiked reactor at each pH level was used for preparing matrix-matched, $\mathrm{pH}$-specific external calibration rows by adding $50 \mu \mathrm{L}$ standard solutions (mixture of MPs at various concentrations in methanol) to $950 \mu \mathrm{L}$ samples. Additionally, compensation of evaporated water was done and operational parameters, including $\mathrm{pH}$, temperature, TSS, and oxygen uptake rates, were measured. Details on the methods and the results are given in Chapter S1 in the SI.

The SEs and AEs were processed in the same way as the BEs except for the following: For the SEs, reactors (100 mL amber Schott bottles) filled with $50 \mathrm{~mL}$ activated sludge were autoclaved twice (24 hours apart) at $121^{\circ} \mathrm{C}$ and $103 \mathrm{kPa}$ for 20 minutes. Triplicate samples of each SE reactor were taken once, approximately two hours after the start of the experiment. For the AEs, reactors (100 mL amber Schott bottles) were filled with $50 \mathrm{~mL}$ activated sludge filtrate (sterile filter: $0.2 \mu \mathrm{m}$, Sartorius Stedium, Göttingen, Germany) and autoclaved in the same way. Samples were taken at $0 \mathrm{~h}$ (in triplicate), $4 \mathrm{~h}, 1 \mathrm{~d}, 2 \mathrm{~d}$, and $3 \mathrm{~d}$ after start. Additional reactors were used to prepare matrix-matched, $\mathrm{pH}$-specific external calibration rows for the SEs and $\mathrm{AEs}$ at each $\mathrm{pH}$ level. 


\section{Analytical Method}

For chemical analysis, reversed-phase liquid chromatography coupled to a high-resolution quadrupole orbitrap mass spectrometer (Qexactive, Thermo Scientific) was used. We adopted an analytical method from Kern et al. (2009) ${ }^{35}$ and adjusted it. Details are reported in Chapter S2 in the SI. Briefly, sample separation was achieved by running a gradient of nanopure water (Barnstead Nanopure, Thermo Scientific) and methanol (HPLC-grade, Fisher Scientific), both augmented with $0.1 \%$ formic acid (98-100\%, Merck), over a C18 Atlantis-T3 column (particle size $3 \mu \mathrm{m}$, $3.0 \times 150 \mathrm{~mm}$, Waters). Detection was done by full scan acquisition (resolution of 70000 and scan range of $50-750 \mathrm{~m} / \mathrm{z}$ ) followed by three data-dependent MS/MS scans (resolution of 17500 ) in electrospray ionization positive-negative switch mode. A matrix blank and a matrix-matched, $\mathrm{pH}$-specific external calibration row over a range from 5 to $100 \mu \mathrm{g} / \mathrm{L}$ with six calibration points were measured prior to the sample series of the corresponding experiments. The lowest calibration point of $5 \mu \mathrm{g} / \mathrm{L}$ was treated as the limit of quantification (LOQ). The triplicate time zero samples of each reactor were used to calculate the method precision with respect to sampling and analysis. The relative recoveries were determined from the time zero samples of the AE reactors.

\section{Estimation of Kinetic Parameters}

In order to compare biotransformation rate constants for a given MP between different pH levels, the observed transformation rate constants were corrected for sorption and abiotic processes with help of the control experiments. To do so, a model describing the contribution of all three processes to the observed decrease of the aqueous concentration of individual MPs was adopted from Helbling et al. (2010b). ${ }^{36}$

$$
C_{\mathrm{aq}}(t)=C_{\mathrm{aq}}(0) \exp \left[-f_{\mathrm{aq}}\left(k_{\mathrm{bio}} T S S+k_{\mathrm{a}}\right) t\right]
$$

where $C_{\mathrm{aq}}(0)$ is the initial aqueous concentration, $k_{\text {bio }}$ the suspended solids concentrationnormalized biotransformation rate constant of the dissolved compound fraction $f_{\mathrm{aq}}$, and $k_{\mathrm{a}}$ the 
abiotic transformation rate constant. For the sake of a simplicity, equation 1 is expressed with the dissolved compound fraction $f_{\text {aq }}$ instead of the sorption coefficient $K_{\mathrm{d}}$ of the original equation. The two parameters can be related to each other by considering the total suspended solids concentration TSS

$$
K_{\mathrm{d}}=\frac{1-f_{\mathrm{aq}}}{f_{\mathrm{aq}} T S S}
$$

with the fraction $f_{\text {aq }}$ defined as

$$
f_{\mathrm{aq}}=\frac{C_{\mathrm{aq}}}{C_{\mathrm{t}}}
$$

where $C_{\mathrm{t}}$ is the total concentration of the compound.

Because various sources of uncertainty had to be taken into account while estimating the kinetic parameters, a Bayesian model allowing for a combination of information in the data with prior knowledge about the parameters was constructed. Equation 1 was applied to model the concentrations measured in the BEs and AEs according to equations 4 and 5.

$$
C_{\mathrm{aq}}^{p, e, r}(t)=C_{\mathrm{aq}}^{p, e, r}(0) \exp \left[-\alpha^{p, e} t\right]+\epsilon^{p, e, r, t}
$$

with

$$
\alpha^{p, e}= \begin{cases}k_{\mathrm{a}}^{p} & \text { if } e=\mathrm{AE} \\ f_{\mathrm{aq}}^{p}\left(k_{\mathrm{bio}}^{p} T S S^{p}+k_{\mathrm{a}}^{p}\right) & \text { if } e=\mathrm{BE}\end{cases}
$$

where the index $e \in\{\mathrm{BE}, \mathrm{AE}\}$ distinguishes biotransformation and abiotic control experiments, $p \in 6,7,8$ distinguishes the three $\mathrm{pH}$-levels, and $r \in 1,2,3$ the three replicates. For every $\mathrm{pH}$-level, values for $k_{\mathrm{bio}}^{p}, k_{\mathrm{a}}^{p}, f_{\mathrm{aq}}^{p}$, and $T S S^{p}$ were inferred across all replicates, while the initial concentration $C_{\mathrm{aq}}^{p, e, r}(0)$ was inferred separately for every single experiment to account for varying spike levels. For further details see Chapter S4 in the SI.

The model was implemented in JAGS $^{37}$ version 3.4.0. JAGS provides Markov chain Monte Carlo samples from the posterior distribution of the parameters. Five chains of 35000 samples 
were generated of which the first 5000 were removed as "burn-in", and thereafter every 10th sample saved for analysis. Each chain was visually inspected to check for convergence. Median as well as $5 \%$ and $95 \%$ percentile values were calculated for $k_{\text {bio, }} K_{\mathrm{d}}$, and $k_{\mathrm{a}}$ from sample values for each MP and each pH level. The resulting $90 \%$ intervals represent parametric, conceptual, and measurement errors. In order to estimate the quality of the fit, root-mean-square error (RMSE) values were calculated for each MP at each $\mathrm{pH}$ level.

\section{Results and Discussion}

\section{Operating Conditions in pH-Controlled Batch Experiments}

The average $\mathrm{pH}$ values for the three $\mathrm{pH}$ levels 6,7 , and 8 measured in triplicate $\mathrm{BE}$ reactors over time were $6.3 \pm 0.3,7.1 \pm 0.2$, and $8.1 \pm 0.2$, respectively. For further analysis, these effective $\mathrm{pH}$ values were used, labeled as $\mathrm{pH} 6, \mathrm{pH} 7$, and $\mathrm{pH} 8$ (see Chapter $\mathrm{S} 1$ in the $\mathrm{SI}$ for more details). The oxygen uptake rates measured on the first day of the experiments at $\mathrm{pH} 6, \mathrm{pH} 7$, and $\mathrm{pH} 8$, were $-20.8 \pm 0.6 \mathrm{mg} /(\mathrm{L} \mathrm{h}),-44.8 \pm 1.0 \mathrm{mg} /(\mathrm{L} \mathrm{h})$, and $-40.8 \pm 1.1 \mathrm{mg} /(\mathrm{L} \mathrm{h})$, respectively. The value at $\mathrm{pH} 6$ was approximately half of the values measured at $\mathrm{pH} 7$ and $\mathrm{pH} 8$. This indicates that the low $\mathrm{pH}$ may have directly affected the activity of at least some members of the microbial community. A strong reduction in activity below 6.7 is, for instance, well-described for nitrifying bacteria. ${ }^{38}$ Therefore, in the following analysis, while the experimental data were analyzed for all pH levels, it needs to be kept in mind that $k_{\text {bio }}$ values at $\mathrm{pH} 6$ might be biased towards low values. This point will be revisited when examining the $\mathrm{pH}$-dependence of the $k_{\text {bio }}$ values of the neutral control MPs.

\section{Concentration Time Series and Kinetic Parameter Estimation}

The concentration time series from the AEs, SEs, and BEs at the three different $\mathrm{pH}$ levels, as shown in Figure 1 for propranolol and for all test compounds in Figure S3-S8 in the SI, show good precision and agreement between replicates (for details on the method precisions and relative 

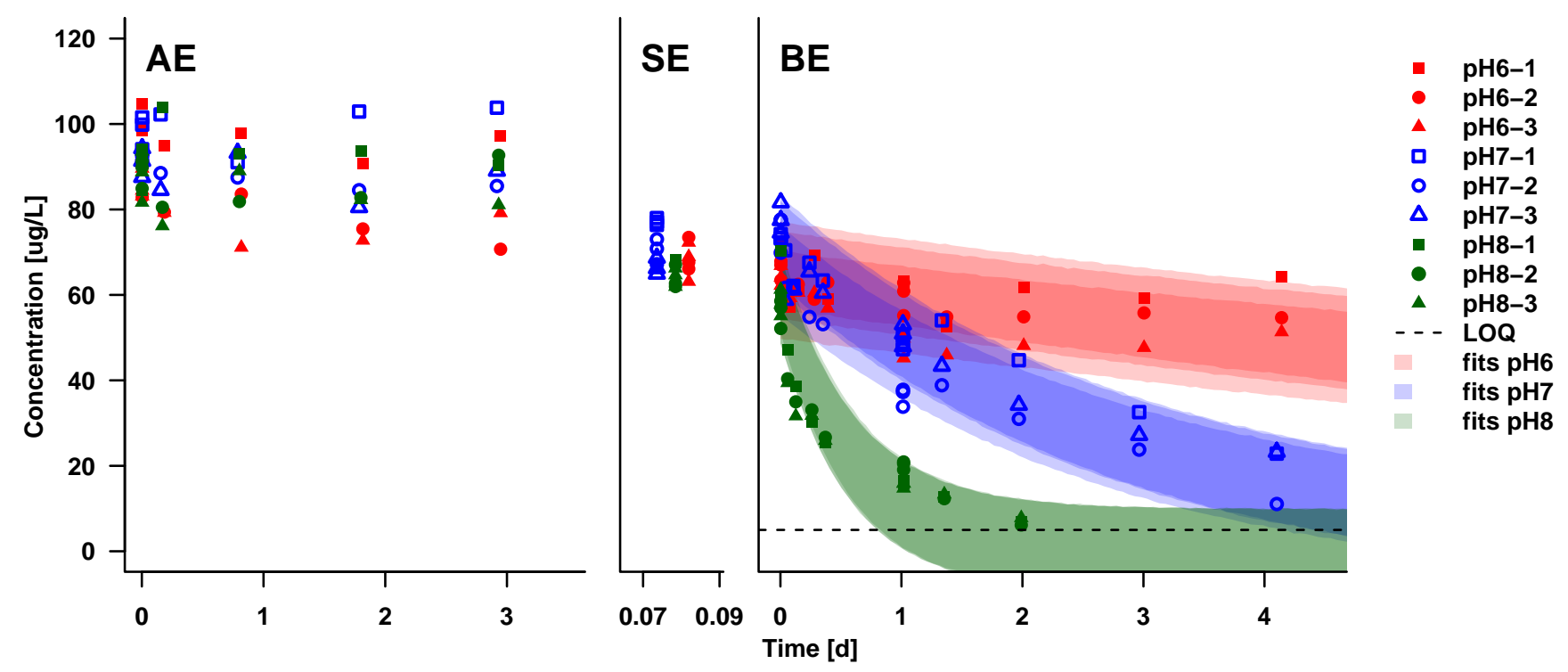

Figure 1: Concentration time series of the abiotic control experiments (AEs), the sorption control experiments (SEs), and the biotransformation experiments (BEs) for propranolol. Each experiment was conducted at $\mathrm{pH} 6$ (red symbols), $\mathrm{pH} 7$ (blue symbols), and $\mathrm{pH} 8$ (green symbols) in triplicate (squares, circles, or triangles). The dashed line at $5 \mu \mathrm{g} / \mathrm{L}$ indicates the limit of quantification (LOQ) below which all measurements were censored. The shaded areas show the $90 \%$ credibility intervals of the model fit to the biotransformation data. The intervals represent parametric, conceptual, and measurement errors and are shown for each replicate. 
recoveries see Chapter S2.1 and S2.2, respectively, in the SI). The AE data for propranolol show hardly any disappearance over time, indicating little abiotic transformation. The same was true for all other MPs, except for pargyline and deprenyl (Figures S3 and S4 in the SI). As is the case for propranolol in Figure 1, the concentrations in the SE were in good agreement with the initial concentrations in the BE for most test compounds. This indicates that autoclaving the sludge did not notably change its sorption capacity for the test chemicals. Furthermore, no noticeable differences in the $\mathrm{SE}$ concentrations at different $\mathrm{pH}$ levels is visible, indicating $\mathrm{pH}$-independence of sorption. As for propranolol, the BE concentration time series of most MPs are clearly different at the three $\mathrm{pH}$ levels indicating a $\mathrm{pH}$-dependence of biotransformation efficiency. This was more quantitatively evaluated by kinetic parameter estimation.

Modeling the concentration data by Bayesian inference was successful for all MPs. The quality of the fits can be assessed based on the $90 \%$ intervals indicated as shaded areas in the $\mathrm{BE}$ graphs (see Figure 1 and Figures S3-S8 in the SI), and by the average deviation of the predicted concentration values from the measured ones, which is discussed in chapter S4.1 in the SI . The kinetic parameter estimation yielded median, $5 \%$, and $95 \%$ percentile values for $k_{\text {bio }}$ and $K_{\mathrm{d}}$, which are illustrated for all MPs in Figure 2 and are listed in Tables S8 and S9 in the $\mathrm{SI}$, respectively. $k_{\mathrm{a}}$ values are given in Table $\mathrm{S} 10$ in the SI.

As can be seen from Figure 2a, $k_{\text {bio }}$ values increased with increasing $\mathrm{pH}$ for cationic-neutral MPs, except for mianserin and nicotine, and decreased with increasing $\mathrm{pH}$ for the neutral-anionic compound trinexapac-ethyl. For a more precise assessment, we defined the effect of $\mathrm{pH}$ as significant if the probability for an increase in $k_{\text {bio }}$ between adjacent values for cationic-neutral MPs or a decrease in $k_{\text {bio }}$ between adjacent values for anionic-neutral MPs was greater than $97 \%$. For neutral MPs both possibilities were tested to assess significance. In Figure 2a, significant differences in $k_{\text {bio }}$ between adjacent $\mathrm{pH}$ levels are marked with asterisks. In total, the effect of $\mathrm{pH}$ was significant for 23 out of $32 k_{\text {bio }}$ possible cases. By comparing the $\mathrm{pH}$ trend of the $k_{\text {bio }}$ values with the trend of the neutral fraction $\left(f_{\mathrm{n}}\right)$, a qualitative correlation of the rate constants with the neutral fraction is clearly apparent. This finding is corroborated by the results for the two neutral 

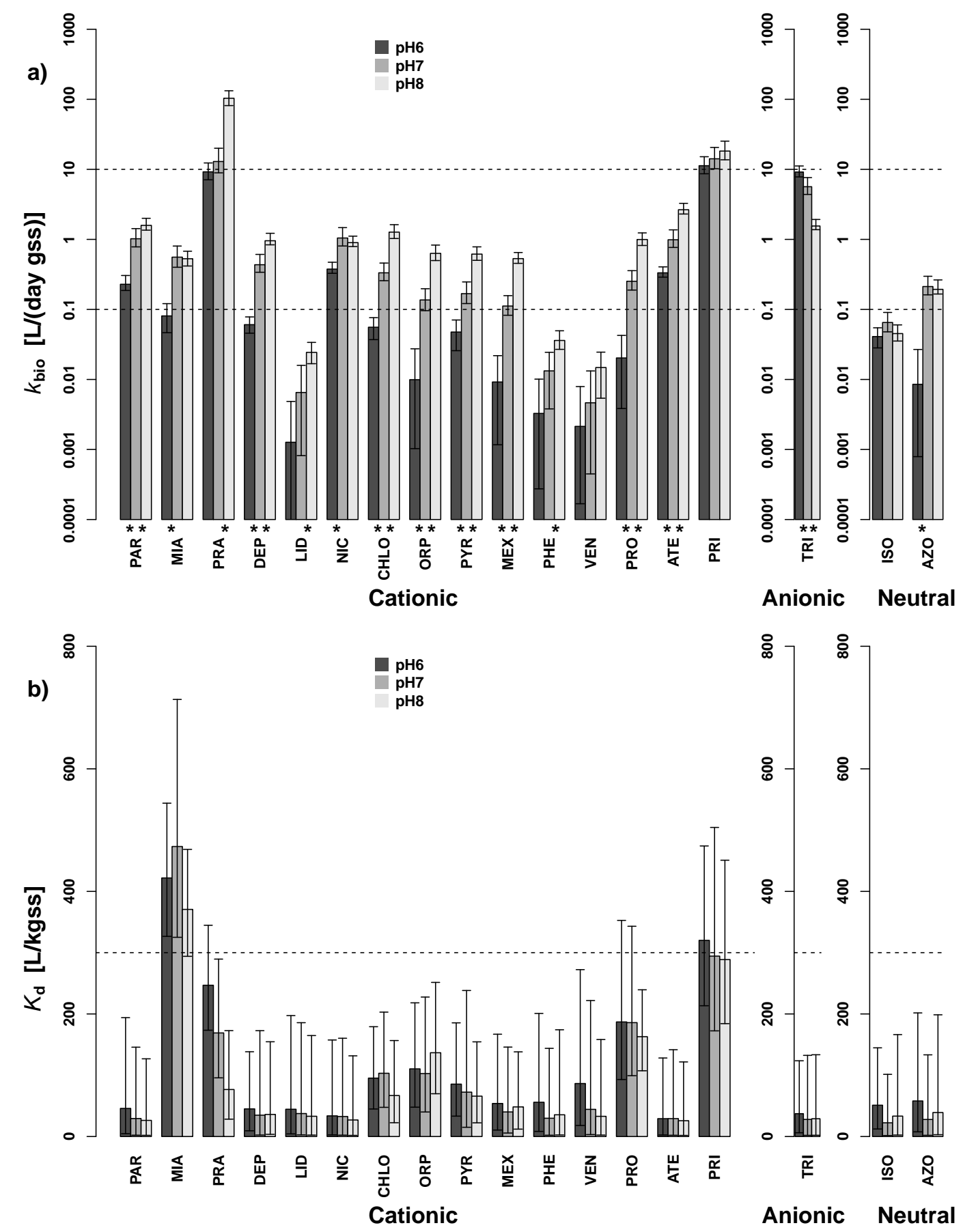

Figure 2: Comparison of (a) biotransformation rate constants $\left(k_{\text {bio }}\right)$ and (b) sorption coefficients $\left(K_{\mathrm{d}}\right)$ at $\mathrm{pH} 6, \mathrm{pH} 7$, and $\mathrm{pH} 8$. Cationic-neutral micropollutants (MPs) are ordered in order of increasing $\mathrm{p} K_{\mathrm{a}}$, followed by the neutral-anionic and the two neutral MPs. The error bars represent the $90 \%$ credibility intervals. The asterisks in (a) indicate a significant change of $k_{\text {bio }}$ values between adjacent $\mathrm{pH}$-levels (see main text for definition). The dashed lines in (a) represent a classification scheme proposed in ${ }^{39}$, wherein $k_{\text {bio }}>10 \mathrm{~L} /\left(g_{S S}\right.$ days) convert to significant removal $(>90 \%), \quad k_{\text {bio }}<0.1 \mathrm{~L} /\left(g_{S S}\right.$ days) convert to no removal $(<20 \%)$, and $k_{\text {bio }}$ values in-between convert to moderate removal of MPs in conventional wastewater treatment plants (WWTPs). The dashed line in (b) represents a limit proposed in ${ }^{20}$, wherein for $K_{\mathrm{d}}$ below $300 \mathrm{~L} / \mathrm{kg}_{\mathrm{sS}}$ no removal through sorption to sludge and subsequent sludge withdrawal is expected in conventional WWTPs. 
MPs, for which the effect of $\mathrm{pH}$ on the $k_{\text {bio }}$ values was not significant for three out of four $\mathrm{pH}$ changes. The only significant change was observed for azoxystrobin at pH6. This is in line with the observed reduced oxygen uptake rate at $\mathrm{pH} 6$, indicating a potential bias towards low $k_{\text {bio }}$ due to a reduced microbial activity at $\mathrm{pH} 6$, which might affect certain biotransformation pathways such as the one of azoxystrobin. Due to this uncertainty at $\mathrm{pH} 6$, the following quantitative interpretation of the observed $\mathrm{pH}$-dependence was restricted to $\mathrm{pH} 7$ and $\mathrm{pH} 8$, which is also the more relevant range for $\mathrm{pH}$ values commonly present in activated sludge systems at WWTPs.

\section{Interpretation of pH-Dependence of Biotransformation Rate Constants}

The simplest explanation for the qualitative correlation of $k_{\text {bio }}$ with the neutral fraction of the ionizable MPs is that charged compounds are inhibited from permeating through the cell membranes and therefore the uptake into the cell is dominated by the uncharged species. This leads to a change in uptake efficiency as a function of $\mathrm{pH}$ and hence an apparent $\mathrm{pH}$-dependence of the observed $k_{\text {bio }}$ values. Thus, we analyzed the data under the following simple assumptions:

i) $\mathrm{pH}$ - and $\mathrm{p} K_{\mathrm{a}}$-dependent speciation in the bulk aqueous phase is established instantaneously after addition of the test compounds; ii) only the neutral species permeates the cell membranes; iii) permeation equilibration is fast compared to biotransformation in the cell, which is the ratedetermining step; and iv) the enzymatic transformation within the cell is independent of the external $\mathrm{pH}$. Hence, the resulting $k_{\text {bio }}$ values measured in the bulk aqueous phase are a function of the neutral fraction in the bulk phase, $f_{\mathrm{n}}$, and the internal biotransformation rate constant, $k_{\text {int }}$ as described in equation 6 for MPs with cationic-neutral speciation (an analogous calculation was done for the neutral-anionic MP).

$$
k_{\text {bio }}(p H)=k_{\text {int }} f_{\mathrm{n}}=\frac{k_{\text {int }}}{\left(1+10^{p K a-p H}\right)}
$$

To compare this simple speciation model against our measured data, we examined the ratios of $k_{\text {bio }}$ values measured at $\mathrm{pH} 7$ and $\mathrm{pH} 8$ since they are independent of the actual internal 
biotransformation rate constant (equation 7).

$$
\text { ratio }=\frac{k_{\text {bio }}(\mathrm{pH} 8)}{k_{\text {bio }}(\mathrm{pH} 7)}=\frac{\left(1+10^{p K a-\mathrm{pH} 7}\right)}{\left(1+10^{p K a-\mathrm{pH} 8}\right)}
$$

Figure 3 shows the comparison of predicted and experimentally determined ratios. The error bars

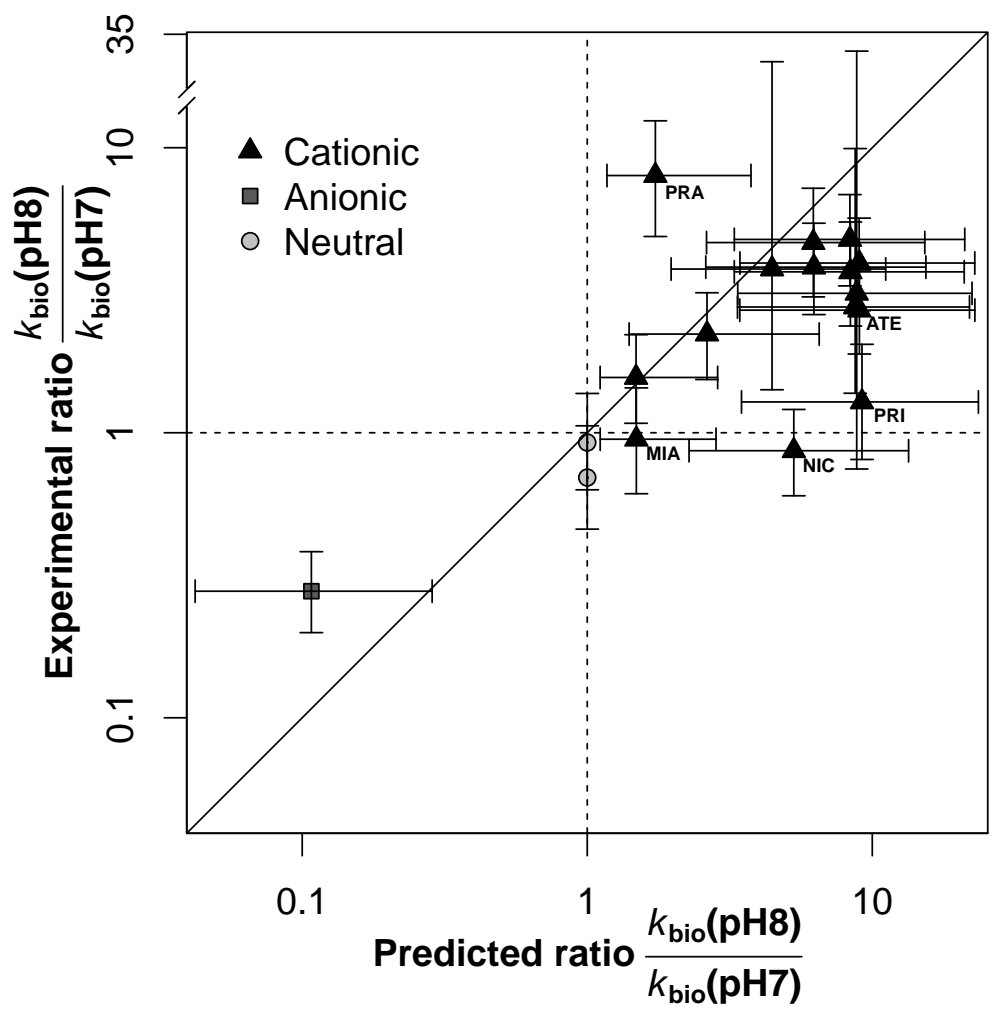

Figure 3: Ratios between the biotransformation rate constants $\left(k_{\text {bio }}\right)$ at $\mathrm{pH} 8$ and at $\mathrm{pH} 7$ as determined experimentally and predicted for all micropollutants (MPs). The predictions were based on the assumption that only the neutral fraction in the bulk aqueous phase permeates through cell membranes and is therefore biotransformed. The dashed lines separate MPs with $k_{\text {bio }}$ values that are decreasing (ratios $<1$ ) and increasing (ratios $>1$ ) from $\mathrm{pH} 7$ to $\mathrm{pH} 8$. The 1:1-line indicates a perfect match between the predicted and experimental ratios. The error bars represent the $90 \%$ credibility intervals of the ratios. The credibility intervals of the five labeled MPs (PRA, MIA, NIC, PRI, ATE) do not overlap with the 1:1-line.

represent the $90 \%$ credibility intervals, which were calculated for the predicted ratios by Monte Carlo Simulation, i.e., by evaluating equation 7 15,000 times with randomly sampled values for $\mathrm{p} K_{\mathrm{a}}$ and $\mathrm{pH}$. For $\mathrm{p} K_{\mathrm{a}}$, a normal distribution around its literature value with a standard deviation of 0.3 was assumed, and the $\mathrm{pH}$ distribution was modeled as a normal distribution with mean 
and standard deviation as determined experimentally. Because the effective $\mathrm{pH}$ values between $\mathrm{pH} 7$ and $\mathrm{pH} 8$ differ by exactly one unit, the predicted ratios (shown on the $\mathrm{x}$-axis of Figure 3 ) can only vary from 1 to 10 for the cationic-neutral MPs, from 0.1 to 1 for the neutral-anionic MP, and are expected to be 1 for the neutral MPs.

As can be seen from Figure 3 , the $90 \%$ credibility intervals of 13 out of 18 compounds overlap with the 1:1-line, indicating considerable agreement between the experimental and predicted ratios of $k_{\text {bio }}$ between $\mathrm{pH} 7$ and $\mathrm{pH} 8$. The five MPs that do not overlap with the 1:1-line are mianserin, pramoxine, nicotine, atenolol, and primaquine. Pramoxine is the only cationic-neutral MP where the ratio of $k_{\text {bio }}$ between $\mathrm{pH} 7$ and $\mathrm{pH} 8$ is considerably underpredicted by the simple speciation model. Pramoxine possesses a comparably small $\mathrm{p} K_{\mathrm{a}}$ value of 7.1 and is therefore already partially neutral at $\mathrm{pH} 7$. Thus, a rather small increase in $k_{\text {bio }}$ from $\mathrm{pH} 7$ to $\mathrm{pH} 8$ was expected. However, the measured increase was one of the largest and no obvious explanation was found for this observation. For all other MPs with cationic-neutral speciation, the experimentally determined ratio tend towards lower values than the simple speciation model predicts. This is most evident for the remaining four outliers. The opposite trend is observed for the

neutral-anionic MP trinexepac-ethyl, which shows a higher experimental ratio compared to the predicted ratios. This means that the simple model is overpredicting the effect of speciation. In other words, the predicted increase in the MPs' degree of speciation in the bulk aqueous phase was more than the observed $\mathrm{pH}$-dependence of the rate constants. Furthermore, when analyzing the relative difference between the predicted and observed ratio of $k_{\text {bio }}$ at $\mathrm{pH} 7$ and $\mathrm{pH} 8$ as a function of $\mathrm{p} K_{\mathrm{a}}$ (see Figure $\mathrm{S} 9$ in the $\mathrm{SI}$ ), we observe increasing relative differences with increasing $\mathrm{p} K_{\mathrm{a}}$. This suggests that, most likely, the contribution of the ionic species to the observed $k_{\text {bio }}$ values is underestimated by the simple speciation model. A similar attenuation of the observed effect compared to the degree of speciation has also been observed in other studies investigating the uptake of ionizable compounds into cells. ${ }^{40-42}$

Thus, the simple speciation model seems to neglect some relevant mechanisms. We acknowledge that some of the assumptions in our speciation model are rather simplistic and the 
mechanisms are known to be more complex. Specifically, with respect to assumption ii), charged compounds are also known to permeate cell membranes, but to a lesser extent than the neutral species. ${ }^{23}$ As to assumption iii), it is discussed that prior to diffusion through the membrane molecules have to diffuse through an unstirred water layer; this step may be part of the ratedetermining step and may be similarly fast for neutral and charged species. ${ }^{40}$ Regarding assumption iv), the transformation within the cell might not be fully independent of the external $\mathrm{pH}^{43}$ While all of these mechanisms can attenuate the effect of a MP's degree of speciation on its biotransformation, our data are currently not sufficient to determine which of these processes occur and how much they contribute.

\section{Interpretation of Sorption Coefficients}

Although the SEs were designed as controls to correct the $k_{\text {bio }}$ values for sorption, we also used them to investigate the potential contribution of sorption to $\mathrm{pH}$-dependent removal of ionizable, polar MPs at the scale of conventional WWTPs. Therefore, we examined the estimated $K_{\mathrm{d}}$ values as shown in Figure $2 \mathrm{~b}$ and listed in Table $\mathrm{S} 9$ in the SI. As can be seen in Figure $2 b$, the $90 \%$ credibility intervals between the different $\mathrm{pH}$ levels overlap for all MPs and the median values typically differ by less than a factor of 2 . Two conclusions can be drawn based on this observation. First, the lack of $\mathrm{pH}$-dependent sorption affinities for the seven MPs that have a $\mathrm{p} K_{\mathrm{a}}>9$ and are therefore nearly completely $(>90 \%)$ positively charged at all $\mathrm{pH}$ levels indicates that the possible increased protonation of the sludge organic matter at lower $\mathrm{pH}$ does not have a relevant influence on the sorption behavior of cationic amines. Second, the lack of $\mathrm{pH}$-dependent sorption affinities for the five MPs that have a $\mathrm{p} K_{\mathrm{a}} \leq 8$ and hence experience substantial changes in speciation over the three $\mathrm{pH}$ levels indicates that the sorption affinity of the charged species does not differ considerably from that of their corresponding neutral species.

A similar observation was also made by Droge and Goss, who examined the effect of $\mathrm{pH}$ on the sorption affinities of compounds with cationic-neutral speciation to natural organic matter at different electrolyte compositions. ${ }^{13}$ They observed close to $\mathrm{pH}$-independent sorption affinities 
if the ionic strength $(150 \mathrm{mM})$ and especially the concentration of divalent inorganic cations (50 $\mathrm{mM} \mathrm{CaCl}_{2}$ ) was high. lonic strength was lower in our experiments at about $15 \mathrm{mM}$ with a concentration of divalent inorganic cations of about $3.5 \mathrm{mM}$. However, since the type of solid organic matter and the test compounds were also different in our experiment, it remains difficult to argue whether the ionic composition can rationalize the observed lack of $\mathrm{pH}$-dependence.

Generally, we observed low sorption coefficients for our test compounds. The $K_{\mathrm{d}}$ values for 16 out of 18 investigated MPs were below $300 \mathrm{~L} / \mathrm{kg}$, which is considered the lower limit for sorption to be a relevant removal process at the scale of conventional WWTPs. ${ }^{20}$ However, these values need to be treated with caution since our experiments were carried out with MP concentrations that were roughly three orders of magnitude higher than those typically found in WWTPs. Therefore, our $K_{\mathrm{d}}$ values are expected to be lower than those observed under more realistic conditions. In conclusion, while our more hydrophobic test compounds could experience some removal due to sorption to sludge and subsequent withdrawal of excess sludge at the WWTP, our data suggest that such a removal by sorption would not show a notable $\mathrm{pH}$-dependence.

\section{Environmental Relevance}

Regarding the removal of ionizable organic MPs in the activated sludge system of a full-scale WWTP, our results highlight some important aspects. First, measured sorption coefficients were typically small indicating that any $\mathrm{pH}$-dependent removal of polar, ionizable organic MPs during activated sludge treatment is more likely an effect of $\mathrm{pH}$-dependent biotransformation than of $\mathrm{pH}$-dependent sorption. This stands in contrast to previous suggestions that variations in sorption to sludge explain $\mathrm{pH}$-dependent removal of MPs with neutral-anionic speciation. ${ }^{9-11}$ Second, biotransformation rate constants did qualitatively correlate with the neutral fraction of the analyzed MPs, but the $\mathrm{pH}$-dependence was not as strong as predicted with a simple speciation model, which assumes that only the neutral species permeate through cell membranes and are therefore biotransformed. Thus, our understanding of the process is not yet sufficient to suggest re-calculating rates observed at one $\mathrm{pH}$ value to other $\mathrm{pH}$ values. Nevertheless, it can be expected 
that the qualitative trend of $\mathrm{pH}$-dependent biotransformation of ionizable MPs is reflected in their removal efficiencies. Thus, a one-unit $\mathrm{pH}$ increase could promote MPs with cationic-neutral speciation from showing no removal to showing moderate removal (see the classification limits proposed by Joss et al. (2006) in Figure $2^{39}$ ). Since close to $50 \%$ of pharmaceuticals contain ionizable functional groups in the relevant $\mathrm{p} K_{\mathrm{a}}$ range, the observed variability in the removal of pharmaceuticals and other ionizable MPs during activated sludge treatment could be partially caused by $\mathrm{pH}$-dependent biotransformation. Therefore, $\mathrm{pH}$-dependent biotransformation should be considered along with other possible factors such as other operating parameters of WWTPs or sludge community composition when interpreting variability in the removal of ionizable organic MPs across different WWTPs.

\section{Acknowledgment}

We thank the operators and staff of the WWTP ARA Neugut for providing activated sludge samples. Additionally, we thank Dr. Adriano Joss for fruitful discussions. Funding for this project was provided by the Swiss National Science Foundation (project 200021_134677).

\section{Supporting Information}

Details on the biotransformation test systems; measurement methods and results for operational parameters, including $\mathrm{pH}$, temperature, total suspended solids concentration, and oxygen uptake rate; details on the analytical method, including method precision and relative recovery; concentration time series of all investigated micropollutants; details on the estimation of kinetic parameters including root-mean-square errors of model fits, estimated biotransformation rate constants, estimated sorption coefficients, and estimated abiotic rate constants; and details on the interpretation of the $\mathrm{pH}$-dependence of biotransfromation. This material is available free of charge via the Internet at http://pubs.acs.org. 


\section{References}

(1) Oulton, R. L.; Kohn, T.; Cwiertny, D. M. Pharmaceuticals and personal care products in effluent matrices: A survey of transformation and removal during wastewater treatment and implications for wastewater management. J. Environ. Monit. 2010, 12, 1956-1978.

(2) Blair, B. D.; Crago, J. P.; Hedman, C. H.; Treguer, R. J. F.; Magruder, C.; Royer, L. S.; Klaper, R. D. Evaluation of a model for the removal of pharmaceuticals, personal care products, and hormones from wastewater. Sci. total Enivorn. 2013, 444, 515 - 521.

(3) Ternes, T. A.; Joss, A.; Siegrist, H. Scrutinizing pharmaceuticals and personal care products in wastewater treatment. Environ. Sci. Technol. 2004, 38, 392A-399A.

(4) Tran, N. H.; Urase, T.; Ngo, H. H.; Hu, J.; Ong, S. L. Insight into metabolic and cometabolic activities of autotrophic and heterotrophic microorganisms in the biodegradation of emerging trace organic contaminants. Bioresour. Technol. 2013, 146, 721-731.

(5) Helbling, D. E.; Johnson, D. R.; Honti, M.; Fenner, K. Micropollutant biotransformation kinetics associate with WWTP process parameters and microbial community characteristics. Environ. Sci. Technol. 2012, 46, 10579-10588.

(6) Eggen, R. L.; Hollender, J.; Joss, A.; Schärer, M.; Stamm, C. Reducing the Discharge of Micropollutants in the Aquatic Environment: The Benefits of Upgrading Wastewater Treatment Plants. Environ. Sci. Technol. 2014, 48, 7683-7689.

(7) Schymanski, E. L.; Singer, H. P.; Longrée, P.; Loos, M.; Ruff, M.; Stravs, M. A.; Ripollés Vidal, C.; Hollender, J. Strategies to characterize polar organic contamination in wastewater: Exploring the capability of high resolution mass spectrometry. Environ. Sci. Technol. 2014, 48, 1811-1818.

(8) Manallack, D. T. The acid -base profile of a contemporary set of drugs: implications for drug discovery. SAR QSAR Environ. Res. 2009, 20, 611-655. 
(9) Urase, T.; Kikuta, T. Separate estimation of adsorption and degradation of pharmaceutical substances and estrogens in the activated sludge process. Water Res. 2005, 39, 1289-1300.

(10) Tadkaew, N.; Sivakumar, M.; Khan, S. J.; McDonald, J. A.; Nghiem, L. D. Effect of mixed liquor $\mathrm{pH}$ on the removal of trace organic contaminants in a membrane bioreactor. Bioresour. Technol. 2010, 101, 1494-1500.

(11) Kimura, K.; Hara, H.; Watanabe, Y. Elimination of selected pharmaceuticals by biosolids from municipal wastewater treatment plants: Importance of modest $\mathrm{pH}$ change and degree of mineralization. Water Sci. Technol. 2010, 62, 1084-1089.

(12) Wang, J.; Huang, C. P.; Allen, H. E. Surface Physical-Chemical Characteristics of Sludge Particulates. Water Environ. Res. 2000, 72, 545-553.

(13) Droge, S.; Goss, K.-U. Effect of sodium and calcium cations on the ion-exchange affinity of organic cations for soil organic matter. Environ. Sci. Technol. 2012, 46, 5894-5901.

(14) Droge, S.; Goss, K.-U. lon-exchange affinity of organic cations to natural organic matter: Influence of amine type and nonionic interactions at two different pHs. Environ. Sci. Technol. 2013, 47, 798-806.

(15) Hörsing, M.; Ledin, A.; Grabic, R.; Fick, J.; Tysklind, M.; la Cour Jansen, J.; Andersen, H. R. Determination of sorption of seventy-five pharmaceuticals in sewage sludge. Water Res. 2011, 45, $4470-4482$.

(16) Hyland, K. C.; Dickenson, E. R. V.; Drewes, J. E. D.; Higgins, C. P. Sorption of ionized and neutral emerging trace organic compounds onto activated sludge from different wastewater treatment configurations. Water Res. 2012, 46, 1958 - 1968.

(17) Karthikeyan, K. G.; Chorover, J. Humic acid complexation of basic and neutral polycyclic aromatic compounds. Chemosphere 2002, 48, 955 - 964. 
(18) Götz, C. W.; Stamm, C.; Fenner, K.; Singer, H.; Schärer, M.; Hollender, J. Targeting aquatic microcontaminants for monitoring: Exposure categorization and application to the Swiss situation. Environ. Sci. Pollut. Res. 2010, 17, 341-354.

(19) Stevens-Garmon, J.; Drewes, J. E.; Khan, S. J.; McDonald, J. M.; Dickenson, E. R. V. Sorption of emerging trace organic compounds onto wastewater sludge solids. Water Res. 2011, 45, $3417-3426$.

(20) Joss, A.; Keller, E.; Alder, A. C.; Göbel, A.; McArdell, C. S.; Ternes, H., T. A.and Siegrist Removal of pharmaceuticals and fragrances in biological wastewater treatment. Water Res. 2005, 39, 3139-3152.

(21) Suzuki, I.; Dular, U.; Kwok, S. C. Ammonia or ammonium ion as substrate for oxidation by Nitrosomonas europaea cells and extracts. J. Bacteriol. 1974, 120, 556-558.

(22) Udert, K. M.; Wächter, M. Complete nutrient recovery from source-separated urine by nitrification and distillation. Water Res. 2012, 46, 453-464.

(23) Eyer, K.; Paech, F.; Schuler, F.; Kuhn, P.; Kissner, R.; Belli, S.; Dittrich, P. S.; Krämer, S. D. A liposomal fluorescence assay to study permeation kinetics of drug-like weak bases across the lipid bilayer. J. Controlled Release 2014, 173, 102-109.

(24) Rendal, C.; Kusk, K. O.; Trapp, S. Optimal choice of pH for toxicity and bioaccumulation studies of ionizing organic chemicals. Environ. Toxicol. Chem. 2011, 30, 2395-2406.

(25) Albert, A., Serjeant, E. P., Eds. The Determination of lonization Constants: A Laboratory Manual, 3rd ed.; Lchapman and Hall: New York, 1984.

(26) JChem for Excel v5.10.1.710 from ChemAxon. http://www.chemaxon.com.

(27) Shalaeva, M.; Kenseth, J.; Lombardo, F.; Bastin, A. Measurement of dissociation constants (pKa values) of organic compounds by multiplexed capillary electrophoresis using aqueous and cosolvent buffers. J. Pharm. Sci. 2008, 97, 2581-2606. 
(28) Mokrosz, J. L.; Pietrasiewicz, M.; Duszynska, B.; Cegla, M. T. Structure-activity relationship studies of central nervous system (CNS) agents. 5. Effect of the hydrocarbon chain on the affinity of 4-substituted 1-(3-chlorophenyl)piperazines for 5-HT1A receptor sites. J. Med. Chem. 1992, 35, 2369-2374.

(29) Lemke, T. L., Williams, D. A., Roche, F. R., Zito, S. W., Eds. Foye's Principles of Medicinal Chemistry, 7th ed.; Lippincott Williams \& Wilkins: Baltimore, 2012.

(30) Avdeef, A., Ed. Absorption and drug development: solubility, permeability and charge state; John Wiley and Sons, Inc.: New Jersey, 2003.

(31) University of Hertfordshire (2013) The Pesticide Properties DataBase (PPDB) developed by the Agriculture \& Environment Research Unit (AERU), .-., University of Hertfordshire http://sitem.herts.ac.uk/aeru/ppdb/en/index.htm(accessedJuly24, 2014).

(32) Helbling, D. E.; Hollender, J.; Kohler, H. P. E.; Singer, H.; Fenner, K. High-Throughput Identification of Microbial Transformation Products of Organic Micropollutants. Environ. Sci. Technol. 2010a, 44, 6621-6627.

(33) Wick, A.; Fink, G.; Joss, A.; Siegrist, H.; Ternes, T. A. Fate of beta blockers and psychoactive drugs in conventional wastewater treatment. Water Res. 2009, 43, 1060 - 1074.

(34) Kern, S.; Baumgartner, R.; Helbling, D. E.; Hollender, J.; Singer, H.; Loos, M. J.; Schwarzenbach, R. P.; Fenner, K. A tiered procedure for assessing the formation of biotransformation products of pharmaceuticals and biocides during activated sludge treatment. J. Environ. Monit. 2010, 12, 2100-2111.

(35) Kern, S.; Fenner, K.; Singer, H. P.; Schwarzenbach, R. P.; Hollender, J. Identification of Transformation Products of Organic Contaminants in Natural Waters by Computer-Aided Prediction and High-Resolution Mass Spectrometry. Environ. Sci. Technol. 2009, 43, 70397046. 
(36) Helbling, D. E.; Hollender, J.; Kohler, H. P.; Fenner, K. Structure-Based Interpretation of Biotransformation Pathways of Amide-Containing Compounds in Sludge-Seeded Bioreactors. Environ. Sci. Technol. 2010b, 44, 6628-6635.

(37) Plummer, M. JAGS: A Program for Analysis of Bayesian Graphical Models Using Gibbs Sampling. 2003; http://www.ci.tuwien.ac.at/Conferences/DSC-2003/Proceedings/, ISSN 1609-395X.

(38) Garardi, M. H., Ed. Nitrification and Denitrification in the Activated Sludge Process, 1st ed.; John Wiley and Sons, Inc.: New York, 2002.

(39) Joss, A.; Zabczynski, S.; Goebel, A.; Hoffmann, B.; Loeffler, D.; McArdell, C. S.; Ternes, T. A.; Thomsen, A.; Siegrist, A. Biological degradation of pharmaceuticals in municipal wastewater treatment: Proposing a classification scheme. Water Res. 2006, 40, $1686-1696$.

(40) Erickson, R. J.; McKim, J. M.; Lien, G. J.; Hoffman, A. D.; Batterman, S. L. Uptake and elimination of ionizable organic chemicals at fish gills: I. Model formulation, parameterization, and behavior. Environ. Toxicol. Chem. 2006, 25, 1512-1521.

(41) Erickson, R. J.; McKim, J. M.; Lien, G. J.; Hoffman, A. D.; Batterman, S. L. Uptake and elimination of ionizable organic chemicals at fish gills: II. Observed and predicted effects of $\mathrm{pH}$, alkalinity, and chemical properties. Environ. Toxicol. Chem. 2006, 25, 1522-1532.

(42) Saarikoski, J.; Lindström, R.; Tyynelä, M.; Viluksela, M. Factors affecting the absorption of phenolics and carboxylic acids in the guppy (Poecilia reticulata). Ecotox. Environ. Safe. 1986, $11,158-173$.

(43) Slonczewski, J. L.; Fujisawa, M.; Dopson, M.; Krulwich, T. A. Cytoplasmic pH Measurement and Homeostasis in Bacteria and Archaea. Advances in Microbial Physiology 2009, 55, 1$79,317$. 